\title{
Correction to: Liver Safety of Fasiglifam (TAK-875) in Patients with Type 2 Diabetes: Review of the Global Clinical Trial Experience
}

\author{
John F. Marcinak ${ }^{1} \mathbb{1} \cdot$ Melvin S. Munsaka ${ }^{1} \cdot$ Paul B. Watkins ${ }^{2} \cdot$ Takashi Ohira $^{3} \cdot$ Neila Smith $^{1}$
}

Published online: 17 October 2018

C) Springer Nature Switzerland AG 2018

\section{Correction to: Drug Saf \\ https://doi.org/10.1007/s40264-018-0642-6}

In the original publication of the article, the ALT and AST values in Fig. 5a-e were capped at 10× ULN, which did not accurately reflect the narrative provided for each case. In this correction, the original Fig. 5a-e (Fig. 1a-e) and the correct Fig. 5a-5e (Fig. 2a-e) are published.

The original article can be found online at https://doi.org/10.1007/ s40264-018-0642-6.

John F. Marcinak

john.marcinak@takeda.com

1 Takeda Pharmaceuticals, Takeda Development Center Americas, Inc., 1 Takeda Pkwy, Deerfield, IL 60015, USA

2 Eshelman School of Pharmacy, Institute for Drug Safety Sciences, University of North Carolina, Chapel Hill, NC, USA

3 Takeda Pharmaceutical Company Limited, 1-1, Doshomachi 4-chome, Chuo-ku, Osaka, Japan 

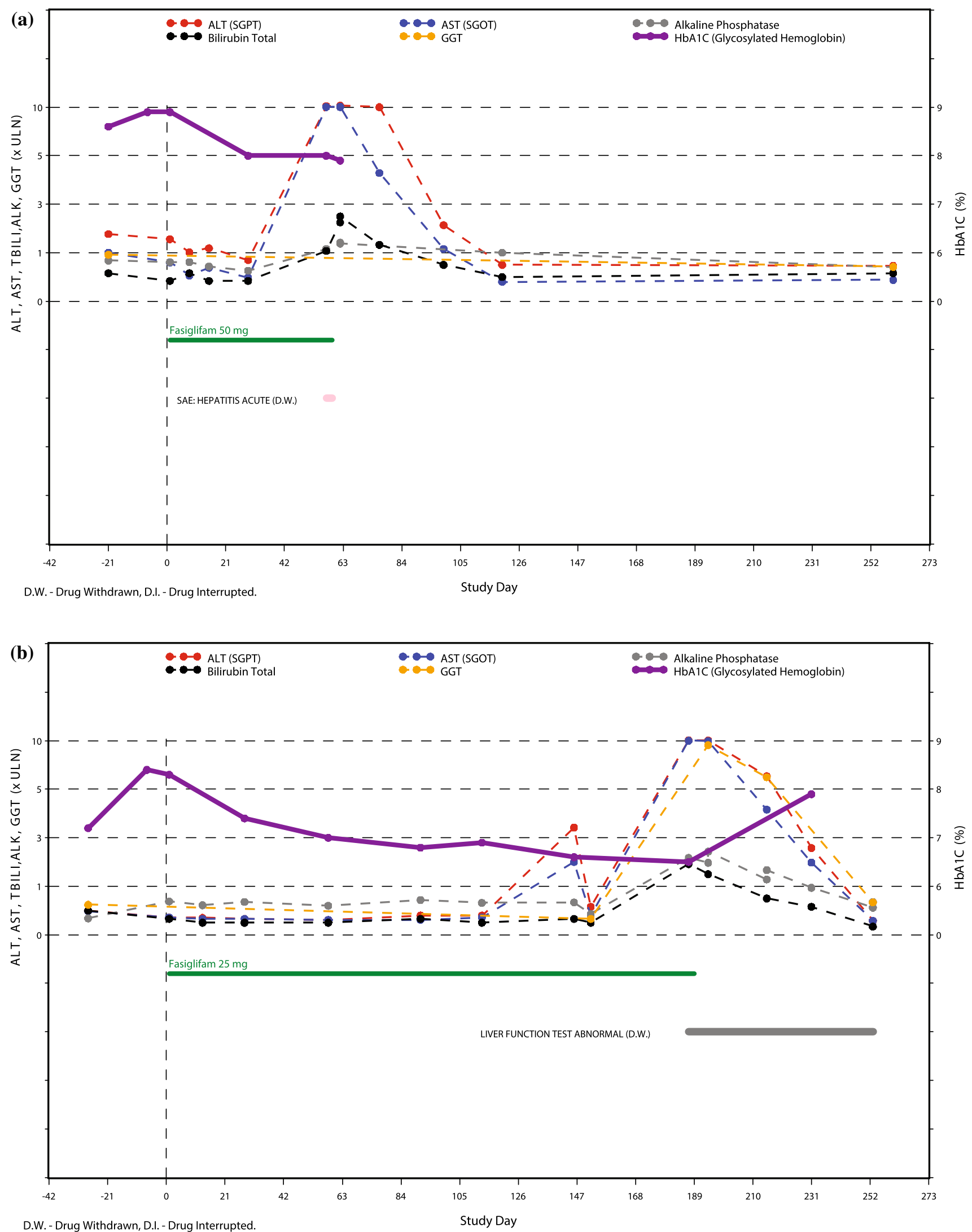

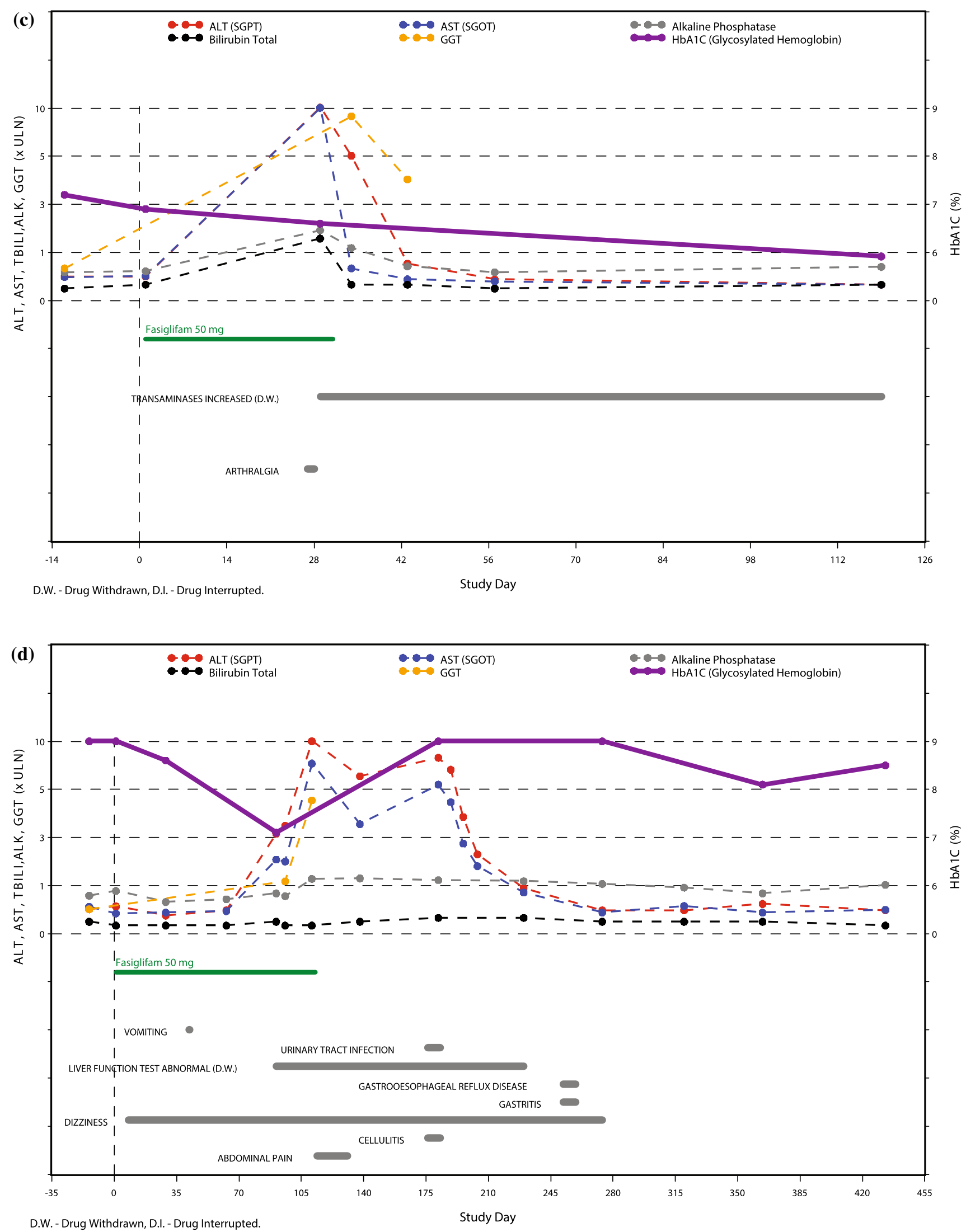


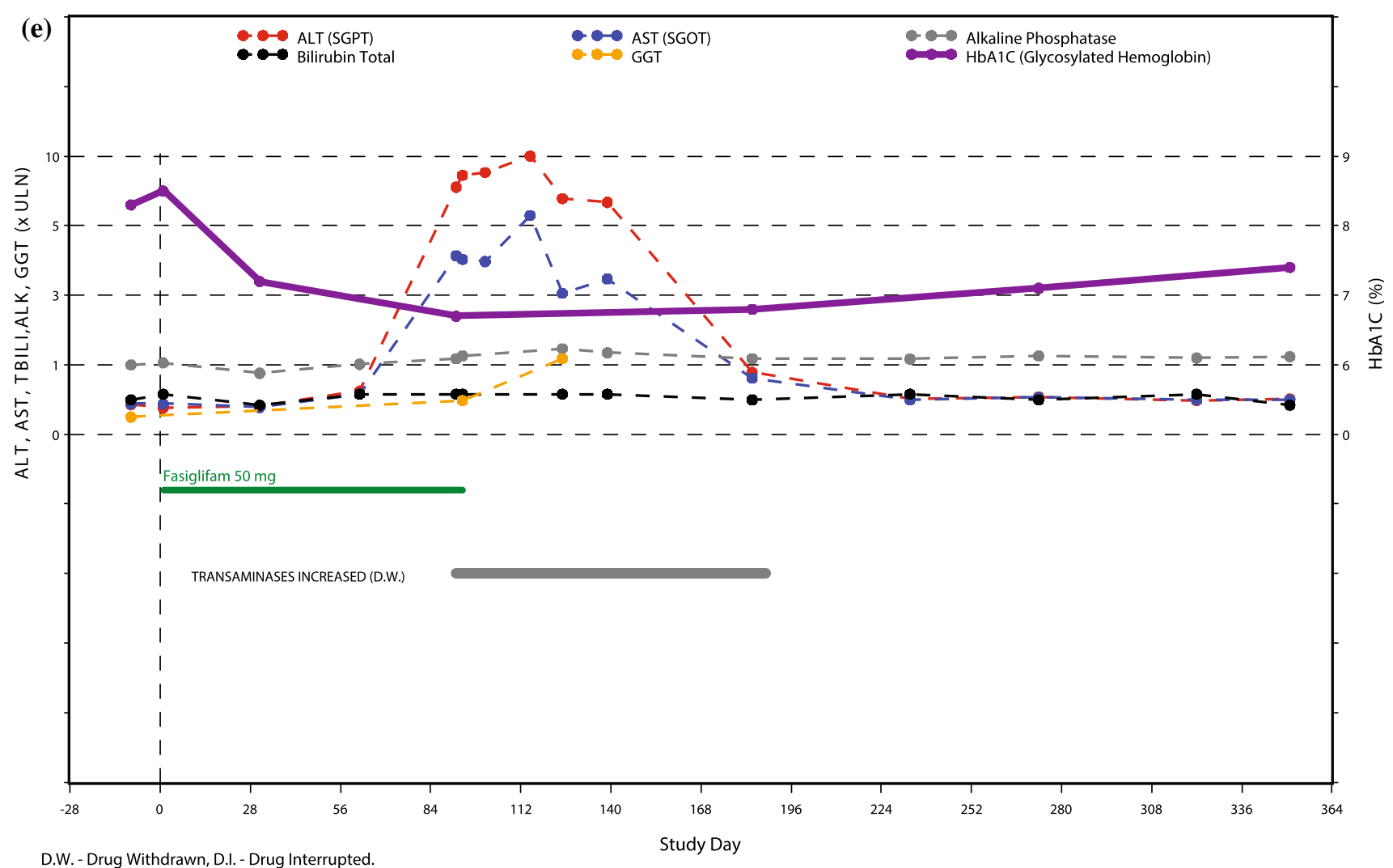

Fig. 1a-e Original version of Fig. 5a-e as published on 28 February 2018 

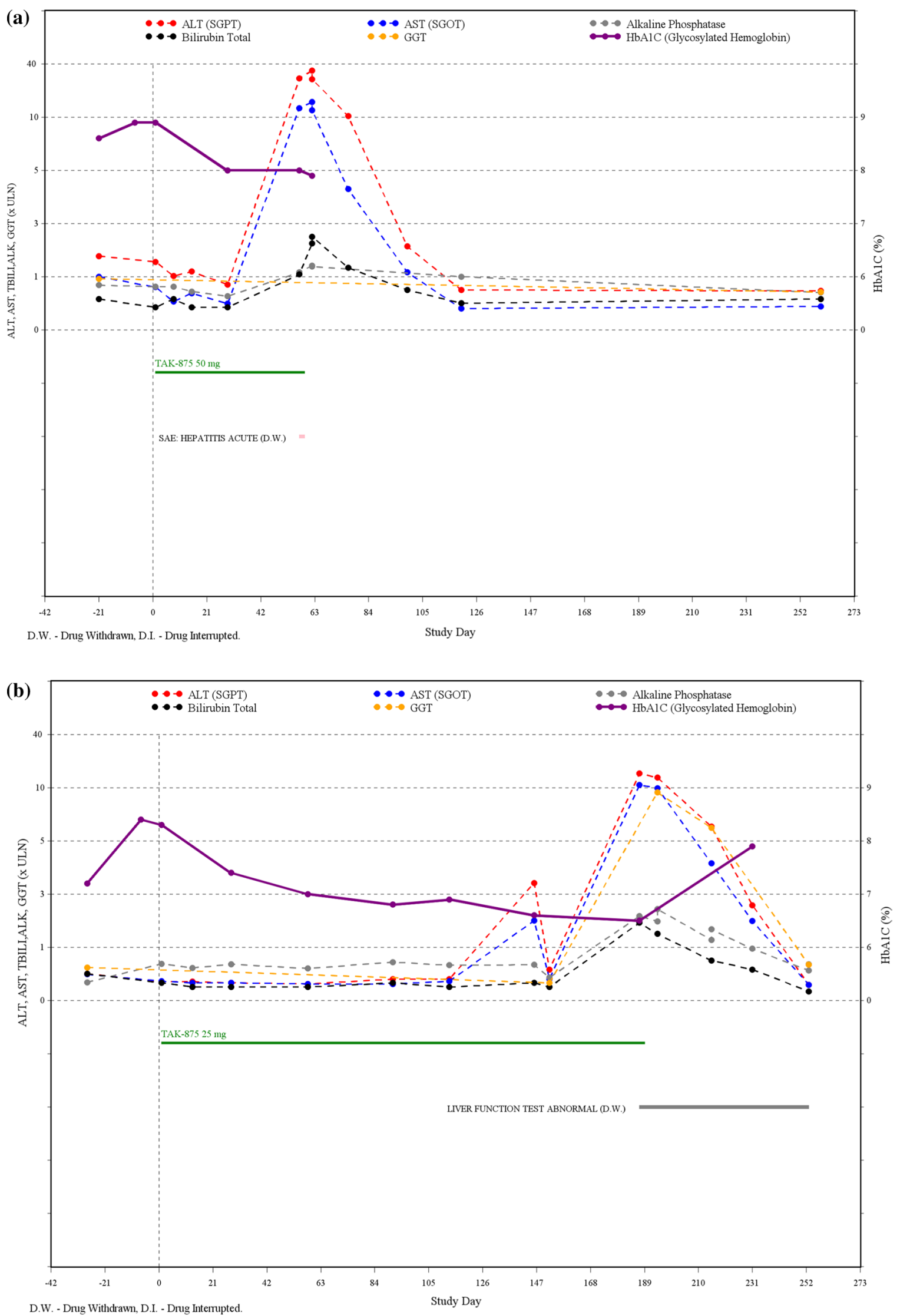




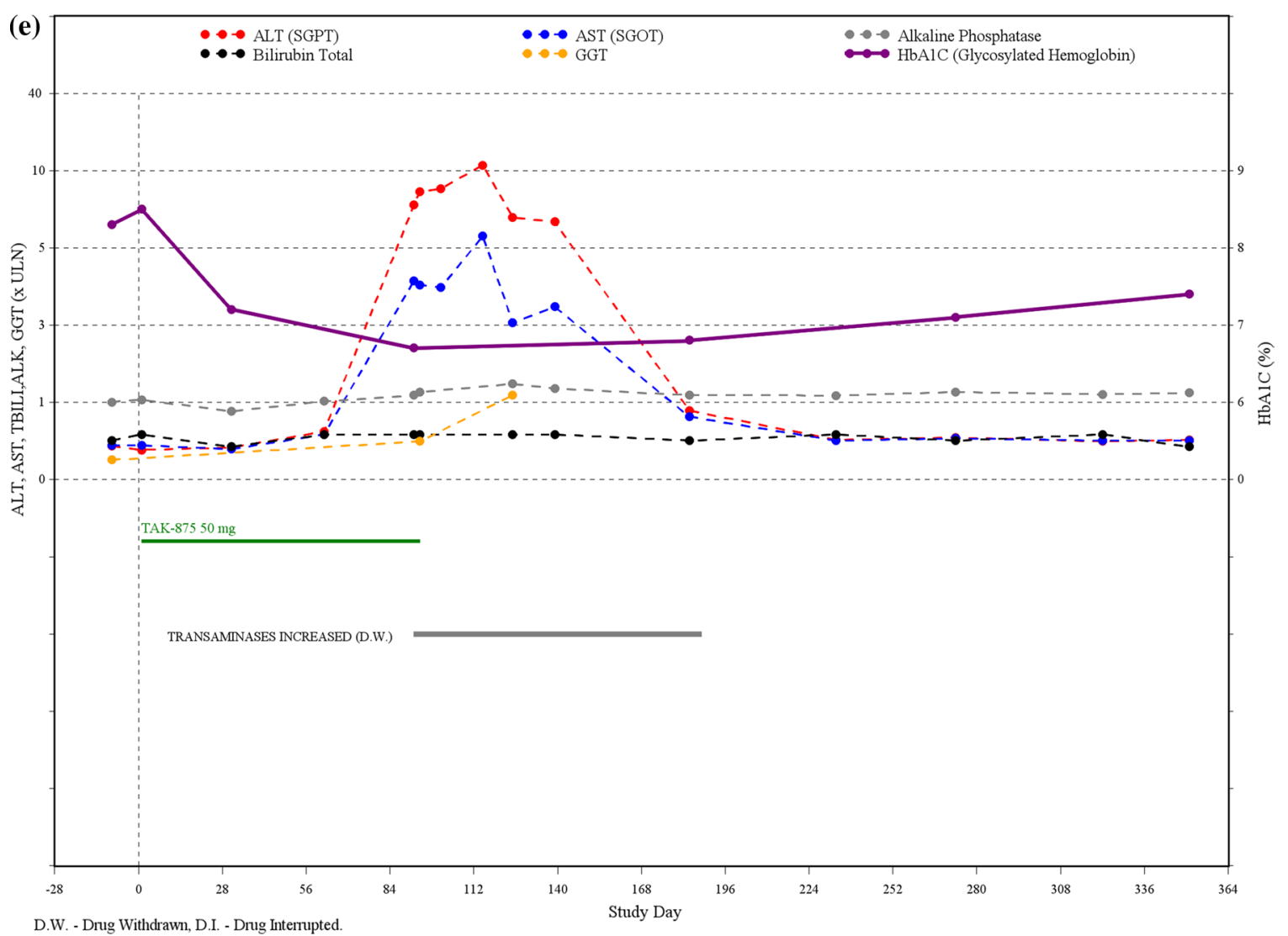

Fig. 2a-e Corrected version of Fig. 5a-e 